\title{
PRESENTACIÓN AL NÚMERO 19
}

Tenemos el placer de presentarles el $\mathrm{N}^{\circ} 19$ de la REJIE, Nueva época. En el primer bloque sobre Innovación docente se incluyen dos artículos de profesores de la Universidad de León, la Universidad Isabel I y la Universidad de Granada. En el segundo bloque, dedicado a la investigación sustantiva, se incluyen cuatro artículos de profesores de Derecho Financiero y Tributario, Derecho del Trabajo y la Seguridad Social y Derecho Mercantil de las Universidades de Málaga y Salamanca.

El primer artículo sobre innovación docente se ha realizado por David Carrizo Aguado, Profesor Ayudante Doctor de Derecho Internacional Privado de la Universidad de León, y $\mathrm{M}^{\mathrm{a}}$ Nieves Alonso García, Profesora doctora de Derecho Constitucional de la Universidad Isabel I. Este artículo lleva por título "Métodos de planificación y práctica docente con herramientas digitales ¿desencuentro con el Reglamento europeo de protección de datos?". En él se analiza, de forma clara y muy práctica, el conflicto entre el intenso y normalizado uso de las TICs en la práctica docente del Derecho y el derecho a la protección de datos de carácter personal previsto constitucionalmente y reforzado tras la entrada en vigor del Reglamento (UE) 2016/679 del Parlamento Europeo y del Consejo de 27 de abril de 2016, relativo a la protección de las personas físicas en lo que respecta al tratamiento de datos personales y a la libre circulación de estos datos. El estudio aborda especialmente la inclusión del Google Calendar como nueva aplicación tecnológica en la planificación docente, la relevancia de los principios de transparencia y limitación del plazo de conservación de los sistemas de evaluación y la publicación de las notas como supuesto de cesión o comunicación de datos. El segundo artículo, que cierra el bloque dedicado a la innovación educativa, lo ha elaborado Rubén López Pico, Becario de Formación Interna en Derecho Procesal de la Universidad de Granada y lleva por título "El cine y la prensa escrita como medios de innovación docente en la enseñanza del Derecho Procesal". El autor presenta en su estudio cómo se puede sustituir el enfoque tradicionalmente atribuido a la docencia práctica, consistente en la resolución por los estudiantes de una serie de supuestos prácticos y en la contestación escrita a las cuestiones planteadas por el profesorado mediante el uso de la legislación, jurisprudencia y bibliografía, por una dinámica basada en la utilización del cine y de la prensa escrita como medios e instrumentos docentes, prácticos e innovadores en la enseñanza y el aprendizaje -respectivamente- del Derecho Procesal. Para ello concreta en su artículo tanto los recursos específicos como la secuencia metodológica a emplear.

El bloque dedicado a la investigación sustantiva se abre con el artículo de Ignacio Cruz Padial, Catedrático de Escuela Universitaria de Derecho Financiero y Tributario de la Universidad de Málaga, cuyo título es "Globalización y crisis económica en la economía social: algunas cuestiones tributarias". En su estudio el autor, en primer lugar, hace referencia a las nuevas formas de financiación (crowfunding, business angels, microcrédito...) que se han generado en los últimos años y analiza en qué medida pueden considerárse como apropiadas para los entes de economía social en el marco del proceso de crisis económica sufrido. En segundo lugar, el autor se refiere a las implicaciones que está ocasionando la economía digital y por ello estudia en qué medida los entes de economía social pueden adaptarse a esta nueva forma de actividad económica, abordando especialmente el supuesto de las cooperativas, por considerar que, junto a las sociedades anónimas laborales, son las que pueden desarrollar una actividad más en la línea o filosofía 
de lo que son empresas de capital. El segundo de los artículos de investigación sustantiva ha sido realizado por Shelagh Anne McKenzie, profesora visitante de la Universidad de Málaga del Departamento de Derecho del Trabajo y la Seguridad Social. Su artículo se titula "Sexual Harassment in the Workplace. A Practitioner's Reflections on the Current Reviews in the United Kingdom post \#MeToo". En él la autora analiza algunos de los debates que se están produciendo actualmente en el Reino Unido sobre el acoso sexual en el entorno laboral tras las denuncias que empezaron a publicarse en prensa en el año 2017 sobre acoso sexual en la industria del entretenimiento. A raíz de estas denuncias y las que les siguieron en otras industrias, la autora examina como el movimiento \#MeToo y el Proyecto "Everyday Sexism", han puesto de relieve hasta qué punto el sexismo, los comentarios y comportamientos sexistas continúan existiendo a día de hoy en la sociedad británica. Del mismo modo la autora estudia los informes que distintas instituciones británicas (the Equality and Human Rights Commission y the Women and Equalities Committee of the House of Commons) han publicado en 2018 sobre el acoso sexual en el entorno laboral en el Reino Unido y cómo estos informes han propuesto reforzar y cambiar las leyes laborales. El tercer artículo lo ha realizado Miguel Ángel Gómez Salado, personal Investigador en Formación FPU del Ministerio de Educación y Formación Profesional, del Departamento de Derecho del Trabajo y de la Seguridad Social, en la Universidad de Málaga. Su estudio lleva por título "Encadenamiento de contratas y responsabilidad empresarial" y en él, el autor analiza las repercusiones que en la gestión y dinámica de las relaciones laborales tiene el encadenamiento de contratas, centrándose concretamente en dos cuestiones: la extensión de la responsabilidad empresarial, y la existencia o no de límites en la cadena de contratas. Finalmente, el artículo de cierre del bloque de investigación sustantiva es el realizado por Cesar Gilo Gómez, Doctor en Derecho por la Universidad de Salamanca y Abogado en ejercicio. Su estudio lleva por título "Las dificultades de la Administración concursal en los concursos de entidades deportivas" y en él se analizan el especial mandato que se encomienda a la Administración concursal cuando la actividad del concursado es la participación en competiciones deportivas. Además el autor, tomando como referencia los precedentes judiciales existentes, examina las decisiones que la Administración Concursal debe adoptar para garantizar la continuidad de la actividad de la entidad, con todas las implicaciones que ello conlleva en cuanto a la necesaria intervención de los poderes públicos y la masa social propia del club en los acuerdos que puedan alcanzarse.

El número se cierra con tres reseñas. La primera de ellas es realizada por Guillermo Sánchez-Archidona sobre el libro Tributación del Crowfunding, cuya autora es María del Mar Soto Moya, profesora de la Universidad de Málaga. La segunda reseña es realizada por Adriana Antúnez Sánchez sobre el libro Sanidad Transfronteriza y Libertad de Circulación, dirigido por la profesora Elsa Marina Álvarez González de la Universidad de Málaga. Y la tercera reseña es realizada por Pedro Aníbal Delgado Rodríguez sobre el libro El soft law como fuente del derecho extranacional, cuya autora es la profesora María Isabel Garrido Gómez de la Universidad de Alcalá.

Esperamos que la Revista siga resultado útil como foro para compartir experiencias de innovación educativa y para tener conocimiento y estar al día de cuestiones actuales y bibliografía reciente en cualquier campo de las disciplinas jurídicas.

Carmen María Ávila Rodríguez

Subdirectora académica de la REJIE, Nueva época 